\title{
Infrared Borescopic Evaluation of High-Energy and Long-Duration Ignition Systems for Lean/Dilute Combustion in Heavy-Duty Natural-Gas Engines
}

\author{
Ahmet Mazacioglu and Michael Gross University of Michigan
}

Justin Kern Bosch

Volker Sick University of Michigan

Citation: Mazacioglu, A., Gross, M., Kern, J., and Sick, V., "Infrared Borescopic Evaluation of High-Energy and Long-Duration Ignition Systems for Lean/Dilute Combustion in Heavy-Duty Natural-Gas Engines," SAE Technical Paper 2018-01-1149, 2018, doi:10.4271/2018-01-1149.

\section{Abstract}

N

atural gas (NG) is attractive for heavy-duty (HD) engines for reasons of cost stability, emissions, and fuel security. NG cannot be reliably compressionignited, but conventional gasoline ignition systems are not optimized for NG and are challenged to ignite mixtures that are lean or diluted with exhaust-gas recirculation (EGR). NG ignition is particularly challenging in large-bore engines, where completing combustion in the available time is more difficult. Using two high-speed infrared (IR) cameras with borescopic access to one cylinder of an HD NG engine, the effect of ignition system on the early flame-kernel development and cycle-to-cycle variability (CCV) was investigated. Imaging in the IR yielded strong signals from water emission lines, which located the flame front and burned-gas regions and obviated image intensifiers. A 9.7-liter, six-cylinder engine was modified to enable exhaust-gas recirculation and to provide optical access. Three ignition technologies were studied: a conventional system delivering $65 \mathrm{~mJ}$ of energy to each spark, a high-energy conventional system delivering $140 \mathrm{~mJ}$, and a Bosch Controlled Electronic Ignition (CEI) system. CEI uses electronics to extend the ignition event, yielding sparks up to $5 \mathrm{~ms}$ in duration with up to $300 \mathrm{~mJ}$ of energy. Air/fuel equivalence ratios, $\lambda$, as high as 1.6 (with minimum EGR) and EGR fractions as high as 23\% (stoichiometric) were tested; ignition delay, engine-out emissions, fuel consumption and image-derived parameters were compared. In most lean or dilute cases, the $140-\mathrm{mJ}$ system yielded the lowest CCV. The imagery provided information about the early stages of ignition and combustion, where pressure measurements are not reliable. Image-based metrics also revealed that early flame kernels located further from the head yielded better combustion, showing that borescopic IR imaging can provide guidance for future engine design.

\section{Introduction and Motivation}

\section{Natural Gas in Heavy-Duty Applications}

In heavy-duty (HD) trucks, compression ignition (CI) is currently the most widespread combustion technology, due to its efficiency and low maintenance requirement. However, the Diesel fuel used in CI engines produces substantial pollutants that require costly and complicated after-treatment. There is a growing interest in replacing Diesel fuel with natural gas (NG), which is a much cleaner fuel. Particular interest exists in the United States, for reasons of fuel cost and fuel security. NG has a significantly higher autoignition temperature $\left(580^{\circ} \mathrm{C}\right)$ than Diesel fuel $\left(210^{\circ} \mathrm{C}\right)$ and a lower cetane number (-10) [1] than Diesel (44-55); hence it is not suitable for CI.
On the other hand, the large octane number (122 Motor Octane Number, [2]) of NG makes it very suitable for spark ignition (SI), due to its knock resistance. Additionally, it is preferred to burn NG in lean conditions to minimize fuel consumption, and also use exhaust-gas recirculation (EGR) to reduce emissions of oxides of nitrogen $\left(\mathrm{NO}_{x}\right)$. However, reaching these goals is challenging, because common sparkignition techniques in current use are not specifically optimized for heavy-duty NG combustion, let alone its lean and EGR-diluted versions. Therefore, it is necessary to use an ignition system that can reliably ignite and ensure complete combustion of lean/dilute NG mixtures. In this document, the effectiveness of three ignition systems is compared using standard measurements based on in-cylinder pressure and measurements made by in-cylinder infrared (IR) imaging. Additional details of the high-speed IR imaging and the quantitative metrics derived therefrom can be found elsewhere [3]. 


\section{Ignition Limits}

Leaner air/fuel mixtures are desirable for improved efficiency, due to more ideal thermodynamic properties of the mixture, reduced pumping work, lower heat losses from lower burnedgas temperatures, and the higher compression ratios that can be reached without knock. However, leaner mixtures require higher ignition energy and some method of accelerating the flame growth so that combustion can be completed during the power stroke. In order to address these requirements, Quader []ㅡ defined two limiting parameters, which are illustrated in Figure 1 [4]: (i) the flame-initiation (or ignition) limit, and (ii) the partial-burn limit. The first limit marks the threshold at which ignition fails, and it is affected by factors that cause flame quenching, such as charge dilution, mixture motion, mixture temperature, compression ratio, spark energy, and the spark plug's heat range and gap. The second limit marks the boundary where the flame-propagation speed becomes too low to complete combustion after the mixture is ignited. The partial-burn limit is affected by charge dilution, mixture temperature, mixture turbulence, and the location and geometry of the spark. Spark-timing selection must be made considering both of these limits. Advanced spark timing prevents partial burns, since advanced timing provides more time for the flame to propagate. Advanced timing also leads to more misfires, especially in leaner mixtures, since the temperatures and pressures early in the cycle are not high enough for flame initiation, and the turbulence level quenches the flame kernel. In contrast, retarding the spark reduces the misfire risk, but it also reduces the available time for flame propagation and hence makes the combustion more susceptible to partial burn. For an ignition system, the goal is to remain in the stable combustion zone, but reaching this goal becomes increasingly challenging as the mixture becomes leaner or more dilute or the combustion chamber becomes larger. Even when the misfire and partial-burn limits are not reached directly, inconsistencies in flow and mixing may yield uneven species concentrations and temperature profiles within the combustion chamber, which eventually leads to cycle-to-cycle variability (CCV) $[\underline{6}, \underline{7}, \underline{8}, \underline{9}]$. CCV is desired to be as low as possible, and ignition selection should be made to enable combustion with minimum instability.

FIGURE 1 The impact on ignition limits of fuel, air/fuel ratio, dilution, and combustion-chamber size. Adapted from [4].

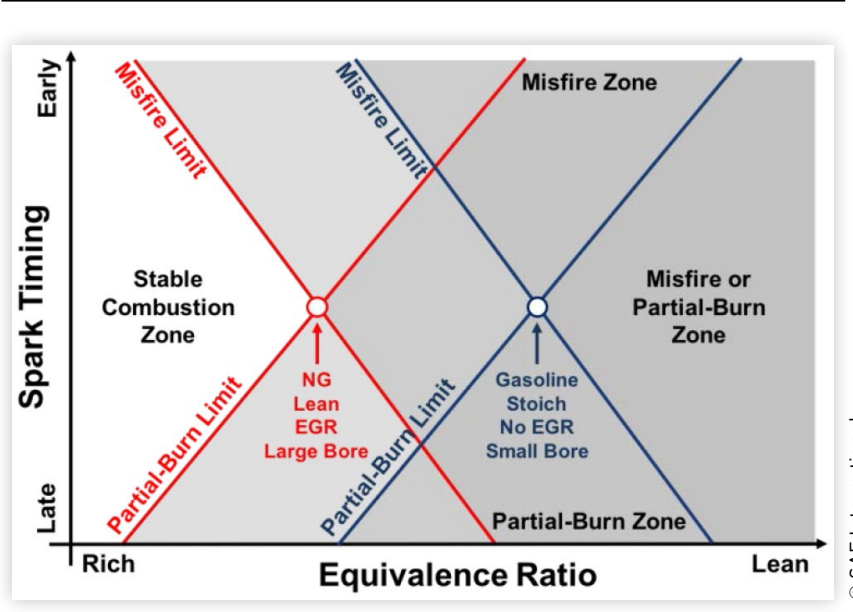

Typically, advanced ignition systems attempt to overcome the ignition limit by increasing either their output energy (e.g., dual-coil ignition [10, 11], Controlled Electronic Ignition [12]) or the effectiveness of the spark-to-gas energy transfer (e.g. microwave-assisted spark ignition [13, 14], corona ignition $[\underline{15}, \underline{16}, \underline{17}]$, nanosecond-pulsed transient-plasma ignition $[\underline{18}$, 19], breakdown ignition [4], laser ignition [20]). On the other hand, these systems attempt to overcome the partial-burn limit by some combination of increasing the flame-propagation rate (e.g., microwave-assisted ignition $[\underline{21}, \underline{22}])$ or reducing the flame-travel distance within the cylinder (multi-plug ignition [23], high-frequency corona ignition $[24,25,17])$.

In the work reported here, three ignition systems were compared. The first was a conventional, inductive-discharge ignition (IDI) system [26] that delivered $65 \mathrm{~mJ}$ to each spark. The second was an IDI system that delivered $140 \mathrm{~mJ}$. The third used a modified circuit to produce a tunable spark duration and thus tunable energy [12].

\section{High-Speed Infrared In-Cylinder Imaging}

Trade-offs exist between different means of optical access. Optically accessible engines provide the best view of the combustion chamber, but they are expensive, limit peak pressure, limit engine speed, can tolerate only short runtimes, and require extensive maintenance. Borescopes provide much more restricted access, but they can be installed in an otherwise production engine and can withstand the peak pressures normally reached by production engines. For this project, it was mission-critical to operate at the pressures and engine speeds of the development engine, so borescopic access was chosen.

There are also trade-offs between different wavelength bands in which to perform optical measurements. Optical diagnostic techniques (e.g., laser-induced fluorescence, laserinduced incandescence, particle-image-velocimetry, shadowgraphy, Schlieren imaging) have been employed in the study of combustion for decades $[\underline{27}, \underline{28}]$. The vast majority of these measurements have been performed in or near the visible band ( 400-700 nm), due to the advanced development level of imaging technology in this band. Silicon is a mature material system, thanks to its use in computer processors, and it offers sensitivity to wavelengths of $\sim 400-1100 \mathrm{~nm}$ [29]. Lens technology is also very mature in the visible band, since consumer cameras work in the visible, which enables sophisticated achromatic compound lenses. By contrast, infrared imaging technology is less mature. However, imaging in the IR offers some crucial benefits that make it attractive for combustion research. First, the near-blackbody radiation produced by soot [이 at combustion-relevant temperatures is much stronger in the IR than the visible. More importantly, the relevant chemical species (e.g., water, carbon dioxide, carbon monoxide) exhibit narrow emission lines in the bands covering 1.0 to $5.5 \mu \mathrm{m}[\underline{31}, \underline{32}, \underline{33}]$. The water lines are of particular interest here. While water is present in the intake charge due to atmospheric humidity, it is found at higher temperature and concentration (both of which yield strong emission) in the volume where combustion has occurred. The significant 
increases in water concentration (due to a peak water production rate of $\sim 15 \times 10^{-3} \mathrm{~mol} /\left[\mathrm{cm}^{3}\right.$-s $]$ for a laminar, stoichiometric, methane/air premixed flame) and temperature ( $\sim$-fold for a laminar, stoichiometric, methane/air premixed flame) across the thickness of the flame front, a distance of approximately $0.5 \mathrm{~mm}$ [34], allow water to serve as a proxy for the location of the flame front and burned-gas region. Since the IR emission lines are so strong, it is often possible to collect sufficient signal without using an intensifier, thus eliminating an expensive, delicate component that reduces spatial resolution. Due to the limited optical access offered by the borescopes, the IR band was selected for this project in order to maximize the available signal.

\section{Experimental Setup}

\section{Engine and Instrumentation}

The parameters of the engine used for these experiments are summarized in Table 1. The Weichai WP10NG engine was modified to enable the various combustion modes needed for this project. It was originally capable of lean NG/air mixtures but had no external-EGR capability. A high-pressure EGR system with an EGR cooler and butterfly-type EGR-control valve was added. The EGR, air, and fuel, were mixed in a custom 3-gas mixer. The original turbocharger was replaced with one (Bosch Mahle Turbo Systems 110 Series) that provided higher backpressure to enable higher EGR rates.

The engine was run in a test cell with an AVL DynoExact dynamometer and AVL Puma Open control and data acquisition system. The cell included an air handler for conditioned combustion air with mass-flow measurement. The cell also included control of coolant temperature and charge air intercooler temperature. Instrumentation on the engine itself included many temperature and pressure sensors, including an AVL combustion pressure sensor in each cylinder, which were read by an AVL Indicom high-speed data-acquisition system. The dynamometer was equipped with high-resolution engine speed and torque measurement. Engine emissions were measured by Horiba MEXA benches sampling raw exhaust before and after the aftertreatment system and diluted in a fullsize dilution tunnel. Intake $\mathrm{CO}_{2}$ concentration was also measured for calculating the external EGR rate. All emission measurements reported here were made before the aftertreatment.

\section{Exhaust-Gas Recirculation}

In this work, the EGR rate is defined to be the ratio of background-corrected intake $\mathrm{CO}_{2}$ concentration to

TABLE 1 The specifications of the Weichai WP10NG engine.

\begin{tabular}{|l|l|}
\hline Cylinder Configuration & Inline 6 \\
\hline Valves per Cylinder & 2 \\
\hline Injection Type & Center-point, 12 injectors \\
\hline Displacement $\left(\mathbf{c m}^{3}\right)$ & 9,726 \\
\hline Bore $\times$ Stroke $(\mathbf{m m})$ & $126 \times 130$ \\
\hline
\end{tabular}

(c) 2018 SAE International. All Rights Reserved. background-corrected exhaust $\mathrm{CO}_{2}$ concentration. The total dilution possible to deliver to the combustion chamber is a combination of EGR and excess air (lean combustion). The air system (including turbocharger, EGR plumbing and valve, charge air cooler, gas mixer, and intake manifold) has a practical limit on the maximum amount of EGR possible for a given quantity of excess air. When running a stoichiometric mixture $(\lambda=1.0)$, the turbocharger does not need to extract a significant amount of power from the exhaust gases, because of the lower boost requirements compared to lean operation. Therefore, this system can achieve up to $30 \%$ EGR rate at specific operating points. When running lean (i.e., $\lambda>1.0$ ), the turbocharger consumes significant power from the exhaust gases, and the intake manifold pressure is much higher, as required to deliver the excess air to the combustion chamber. These factors limit the amount of EGR that is possible to push from the exhaust manifold to the intake manifold, to approximately $12 \%$ maximum, depending on operating point.

The measured EGR rate with the EGR valve completely closed was between $2 \%$ and $4 \%$. This nonzero value results from residual $\mathrm{CO}_{2}$ in the intake manifold from leakage past the EGR valve and possibly re-aspirated exhaust gases in the intake manifold. Thus, no operating conditions with $0 \%$ EGR were measured. The current configuration of the air system also limits maximum EGR rate. The concept of the project of which this work is a part is to determine how much dilution can be used with each of several ignition systems, with the goal to have increased engine efficiency and low engine-out emissions at an optimized high-dilution mixture. At some operating points, however, the air system does not have enough dilution capability to test the limit of the ignition system. For future work at all operating points, an air system with higher EGR or boost pressure capability would be recommended. This could be achieved with a multiturbocharger air system, a variable geometry turbocharger, or a positivedisplacement EGR pump could be utilized.

\section{Ignition Systems}

The unmodified form of this engine relied on a conventional, IDI system with coils delivering $65 \mathrm{~mJ}$ of energy during each spark. The systems tested here are summarized in Table 2 . The standard spark plugs were used for all three ignition systems, only the components between the engine control unit and the plugs were replaced.

Conventional Ignition Systems For the two conventional, IDI experiments described here, the engine was equipped with Bosch coils (functional samples not intended

TABLE 2 The parameters of the ignition systems studied here.

\begin{tabular}{|llll} 
& $\begin{array}{l}\text { Spark Energy } \\
{[\mathbf{m J}]}\end{array}$ & $\begin{array}{l}\text { Spark } \\
\text { Duration } \\
{[\mathbf{m s}]}\end{array}$ & $\begin{array}{l}\text { Peak Spark } \\
\text { Voltage } \\
{[\mathbf{k V}]}\end{array}$ \\
\hline $\begin{array}{l}\text { Ignition System } \\
\text { 65-mJ Conventional }\end{array}$ & 65 & 1.9 & 30 \\
\hline $\begin{array}{l}\text { 140-mJ Conventional } \\
\text { Ignition }\end{array}$ & 140 & 3.45 & 40 \\
\hline
\end{tabular}


for production) that could deliver up to $140 \mathrm{~mJ}$. The coils allowed the dwell time (during which the coils are charged) to be adjusted for operation at $65 \mathrm{~mJ}$ (simulating the stock system) or at $140 \mathrm{~mJ}$ without a hardware change. The $140-\mathrm{mJ}$ setting produced both a higher voltage and a longer duration, compared to the $65-\mathrm{mJ}$ case.

Controlled Electronic Ignition The third system was Bosch Controlled Electronic Ignition. The CEI discharge goes through the same breakdown, arc, and glow phases as any other spark-plug-based ignition system, but CEI uses a modified circuit producing an extended glow phase that is tunable in duration [12], as illustrated by the current-time cartoon in Figure 2. The current is nearly constant during the extended glow time and then decays in the normal way afterward. The glow times reported here are the extended glow times, which exclude the natural decay and thus underestimate the total glow-phase. The voltage-time curve [12] is more structured than the current-time curve; the voltage is $37-45 \mathrm{kV}$ during the breakdown phase but drops to $\sim 1 \mathrm{kV}$ during the arc phase, after which it fluctuates with an amplitude of $\sim 1 \mathrm{kV}$ throughout the remainder of the discharge. The energy delivered by CEI was claimed by the manufacturer to be $50-300 \mathrm{~mJ}$, depending on the dwell and glow times, which were separately adjustable over 0.4-1.6 ms and 0.3-5.0 ms, respectively. CEI is a proprietary, prototype system, so no additional detail on its inner workings are available. The initial voltage and spark duration produced by CEI is comparable to that of the 140-mJ IDI system; the additional energy (up to about 2 times as much) comes about because the voltage remains at the initial value throughout most of the spark event, rather than experiencing an exponential decay. This high-voltage, constant-current, long-duration discharge enhances Joule heating and reduces the risk of misfire, making CEI a good candidate for EGR-diluted, lean, low-cetane mixtures and cold starts. The potential drawbacks of CEI are increased heat losses through the electrodes and faster electrode erosion due to the longer spark duration.

\section{Optical Access and Imaging Equipment}

Conveniently, the engine was equipped with an individual head for each cylinder. The head of Cylinder 6 was modified to provide optical access for two cameras, as illustrated by the drawing in Figure 3 and the photograph in Figure 4; borescope

FIGURE 2 Secondary-current behavior of the conventional and CEl systems.

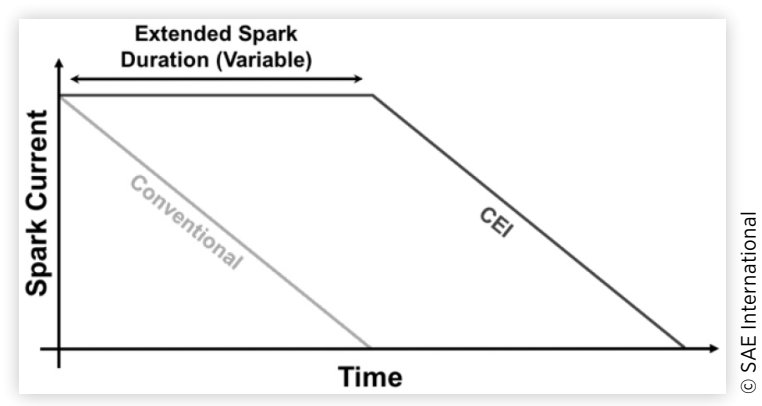

sleeves were installed in the head, and reliefs were cut into the top of the piston to provide clearance for the borescope tips. The positions of the valves, spark plug, ports, coolant passages, and intake manifold, prevented the borescopes from being positioned orthogonally; the angle between the borescopes, measured about the vertical axis, was $\sim 70^{\circ}$.

The borescopes, sleeves, and related hardware were purchased from AVL. The borescopes' outside diameter is $7 \mathrm{~mm}$, and they are optimized to focus light of wavelengths between 1.0 and $1.7 \mu \mathrm{m}$. The borescopes were cooled with air at $\sim 6$ bar pressure that was first passed through an AVL filter unit, which removed particles that could clog the cooling channels. The borescopes were protected from the heat and pressure in the chamber by sapphire windows.

Each camera was a Xenics Cheetah-640-CL with the VisNIR option. The sensor chip has $640 \times 512$ monochrome pixels with 12 bits of digitization depth and is sensitive to wavelengths between 0.4 and $1.7 \mu \mathrm{m}$ (with maximum sensitivity between 1.0 and $1.6 \mu \mathrm{m}$ ), enabling the detection of strong water emission lines. The borescopes do transmit visible light, but the focus is poor in that band. After some experimentation, a $1-\mu \mathrm{m}$ long-pass filter was placed between each borescope and its camera to provide the best image clarity. The spark's light was almost entirely in the ultraviolet and the visible, so it was not

FIGURE 3 A top-down drawing showing how the cameras are mounted on the engine. Camera 1 is mounted on a borescope inserted into the right side of Cylinder 6 , while Camera 2 is mounted on a borescope inserted from the rear.

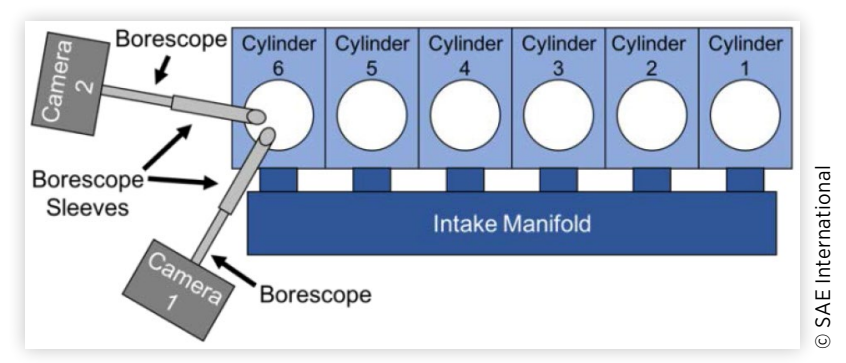

FIGURE 4 An annotated photograph of the modified head of Cylinder 6 showing the relative positions of the two borescopes and head features.

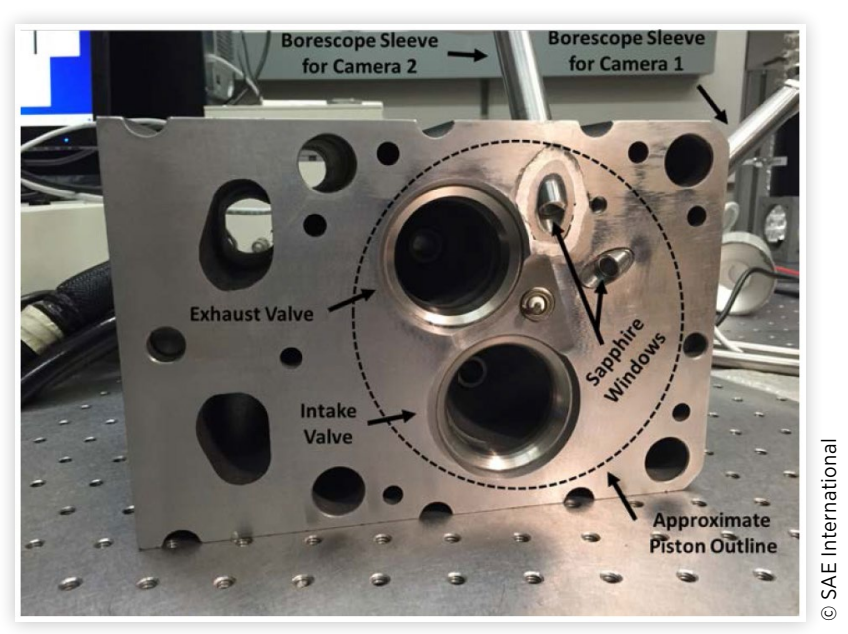

(c) 2018 SAE International. All Rights Reserved. 
detectable by the filtered camera. Initial experiments found that the field of view (FoV) of each borescope occupied $<2 / 3$ of the camera sensor in each dimension, so both cameras were windowed to $384 \times 336$ pixels, enabling frame rates $>1 \mathrm{kHz}$. Each camera was held fixed relative to its borescope and the engine using a combination of AVL-supplied and custom-fabricated hardware. Each sapphire window was cleaned and each borescope was repositioned within its sleeve before each experiment; the distance from the tip of the borescope to the window was adjusted to provide adequate flow of cooling air. For the 65-mJ ignition system, the borescope of Camera 1 was placed 1-2 mm farther from the window than in the other two cases, resulting in slightly smaller flame images. Preliminary imaging revealed reflections of the flame kernel from the piston top. To reduce these reflections, the piston top and head were painted with flat black VHT Flameproof high-temperature coating.

One-per-cycle and 1440-per-cycle signals were input to a LaVision PTU-X programmable timing unit, which triggered the cameras simultaneously for each image capture. One instance of LaVision Davis 8 was used to program the timing unit and record images from Camera 1; a second instance of $\mathrm{DaV}$ is captured images from Camera 2. Only Camera 1's images will be discussed in this document.

\section{Experimental Procedure}

\section{Engine Calibration}

It is desirable to determine the maximum dilution for each operating point, as the most dilute mixture potentially offers the best efficiency. Since burning more dilute mixtures increases CCV, a maximum acceptable CCV must be specified before determining the maximum dilution. For these experiments, that maximum CCV was defined to be the coefficient of variation of indicated mean effective pressure (CoV(IMEP)) $<6 \%$ for each cylinder. Despite the modifications made to Cylinder 6, the highest CoV(IMEP) were found in Cylinders 3 and 4 . The high CCV in the center cylinders is attributed to incomplete air/fuel mixing in the intake manifold, resulting in a poorly mixed or globally lean mixture reaching those cylinders. In this paper, the CoV(IMEP) of Cylinder 6 are reported, since this parameter will be compared with images recorded from that cylinder. Measurements of fuel consumption and emissions are reported for the engine as whole.

For each operating point defined by engine speed, load, $\lambda$, and EGR, the spark timing was adjusted to position $\mathrm{MFB}_{50}$ at $\sim 9$ crank angle degrees after top dead center ( ${ }^{\circ}$ aTDC) for every cylinder. (In this document, $\mathrm{MFB}_{x}$ refers to the crank angle at which $\mathrm{x} \%$ mass fraction of the fuel has been burned.) This $\mathrm{MFB}_{50}$ target was determined from timing sweeps at many operating points to be the value that minimized the brake-specific fuel consumption. All measurements reported here were made at $1000 \mathrm{rev} / \mathrm{min}$ and an IMEP of $6.8 \mathrm{bar}$.

\section{Data and Image Acquisition}

Before comparing the three ignition systems, the operating points summarized in Table 3 were examined with only CEI
TABLE 3 The conditions tested and the parameters measured during set up of the CEI system. The engine speed and IMEP were $1000 \mathrm{rev} / \mathrm{min}$ and $6.8 \mathrm{bar}$. Each column is color-coded from red (the lowest value) to blue (the highest).

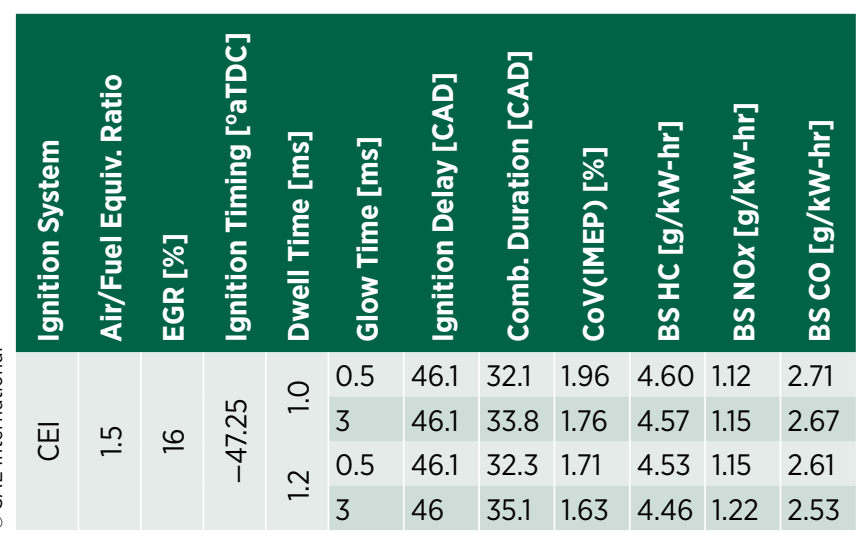

in order to understand the effect of the glow and dwell times on ignition and to select the values that would be used for the comparison. Only durations on the long end of the range for each parameter were used, based on guidance provided by the CEI engineers at Bosch. These engineers stated that shorter durations did not yield reliable ignition while longer durations did not improve combustion. Based on the outcomes of these preliminary experiments, described below in the Results and Discussion section, the dwell and glow time were set to 1.0 and $3.0 \mathrm{~ms}$, respectively, for all later experiments.

The operating conditions for directly comparing all three ignition systems are summarized in Table 4. At each operating

TABLE 4 The operating conditions tested and parameters measured with all ignition systems. The engine speed and IMEP were $1000 \mathrm{rev} / \mathrm{min}$ and $6.8 \mathrm{bar}$. Each column is color-coded from red (the lowest value) to blue (the highest).

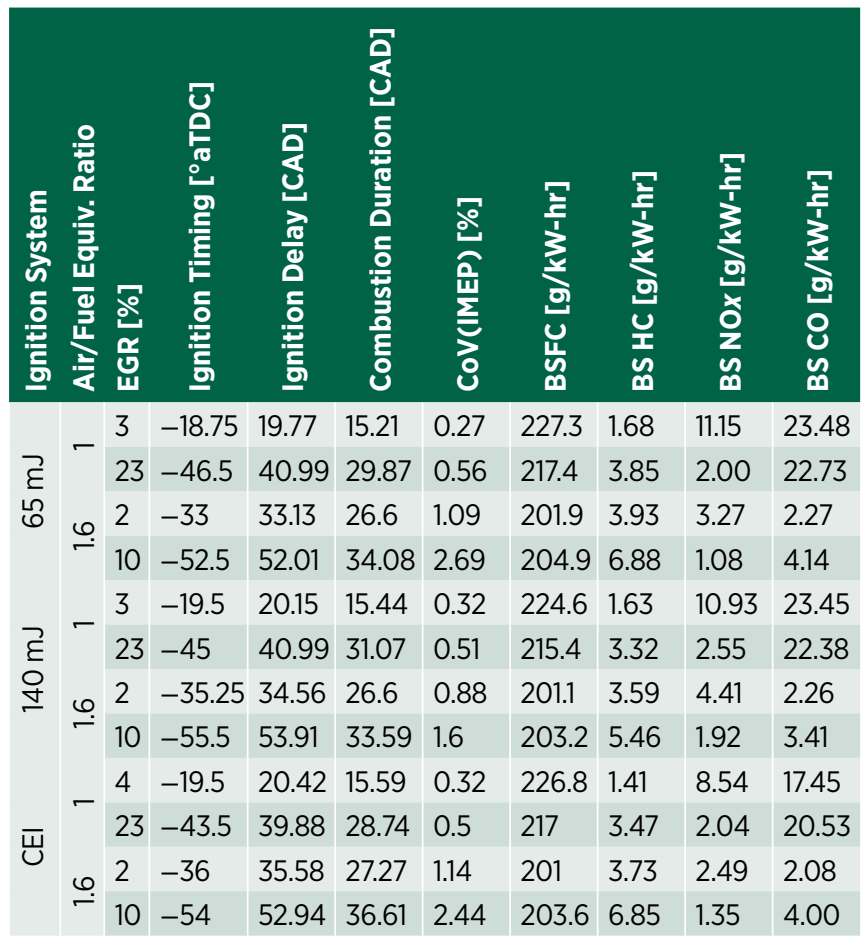


point, the in-cylinder pressure and images were recorded over a 100-cycle period. The statistical metrics reported here were computed from these 100-cycle measurements. Images were recorded at intervals of 5.5 CAD, equivalent to a frame rate of $1.09 \mathrm{kHz}$. For each operating condition, multiple measurements were made, each with a different timing offset (multiples of 0.5 or $1.0 \mathrm{CAD}$, depending on the experiment). Due to CCV, the images cannot be simply interleaved to fill in the gaps in the imaging. However, since 100 cycles of images were recorded at each offset, these images can be used to provide statistical information at 0.5- or 1.0-CAD resolution, as will be described in the next section. Images were recorded from just before ignition to the point at which the FoV was filled with flame. Operating points that were lean or diluted necessitated earlier ignition timing and burned later, thus longer imaging periods were required.

The camera integration time was chosen to provide the best signal-to-noise ratio for each operating condition; these times ranged from 10 to $20 \mu \mathrm{s}$, much shorter than the frame period of $920 \mu \mathrm{s}$. The cameras did not offer the capability of changing the integration time during the engine cycle, so the chosen integration time was necessarily a compromise between sensitivity during the very early flame development and ability to image late in the cycle before being overwhelmed by saturation. Because saturation occurred in later images (beginning around $\mathrm{MFB}_{00.5}$ ), it was not possible to correct for different exposure times by simple multiplication of the counts in each pixel; all that is known about the saturated pixels is that the number of counts generated is greater than or equal to the maximum possible for the camera, so multiplying them to below-saturation levels would be misleading.

\section{Image Processing and Analysis}

Image processing was carried out using a combination of LaVision DaVis and MathWorks MATLAB, as illustrated briefly in Figure 5 and in detail elsewhere [3]. (Note that the processed image in Figure 5 includes labels for some of the features visible in the image.) Although the cameras have monochrome sensors, false color was applied in many images presented here to improve clarity. The processing began with the raw image recorded by the camera. A background image, recorded immediately before ignition, was subtracted from the raw image to reduce the noise. A median filter with a $3 \times$ 3 -pixel window was applied to smooth the image. Otsu's method of thresholding [35] was applied to reduce the reflections that were still visible, despite the matte black coating on the piston. Values below the threshold were set to 0 ; those above were set to 1 , resulting in a binarized image. The filtered image was multiplied by the binarized image, creating the thresholded final image.

The collection of all images recorded at a given crank angle during each 100-cycle measurement is called a "subset" here. Each subset was averaged to create a mean image for each crank angle. A standard deviation image was calculated from the binarized images in each subset. The location of the centroid (center of mass) was computed for each frame by weighting each pixel according to its brightness. A "centroid
FIGURE 5 A sample raw image along with its processed counterpart. Relevant features are annotated in the bottom image.

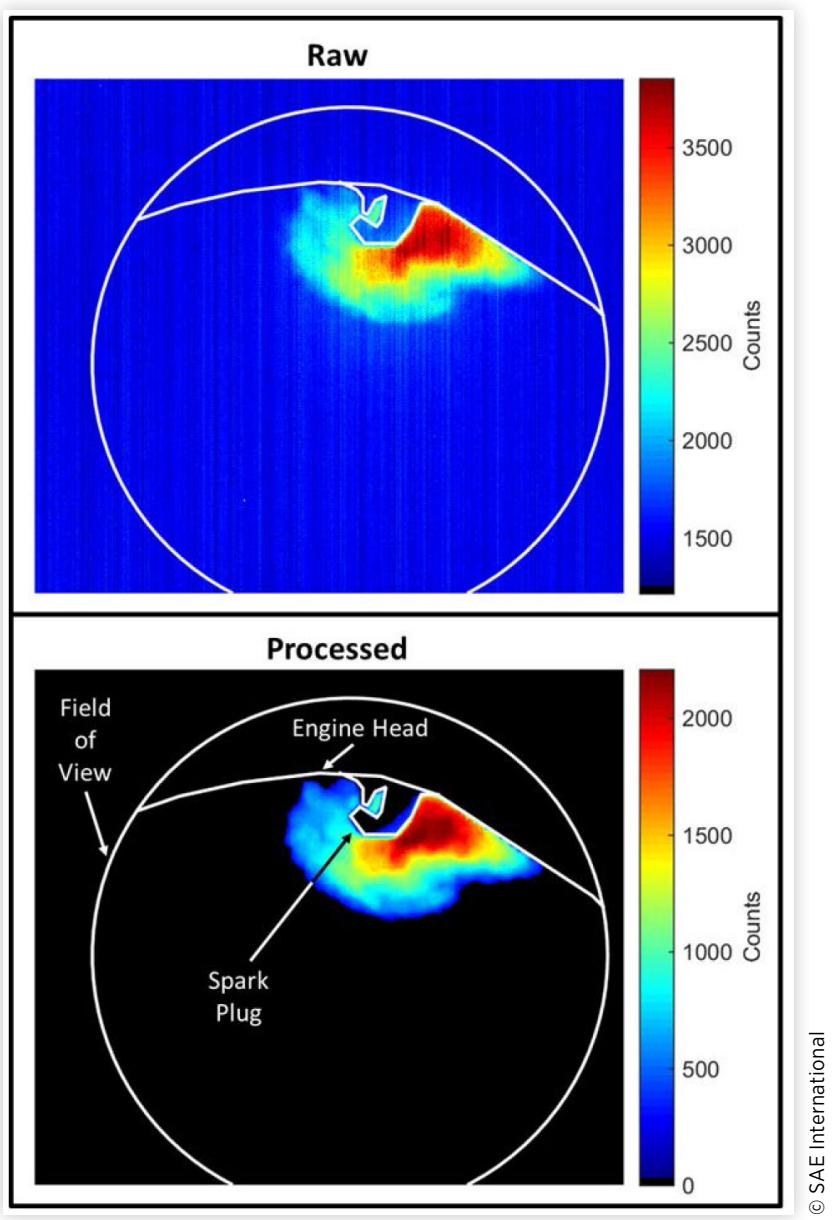

cloud" was created for selected subsets by plotting the centroid of each image (marked with a circle that was color-coded by the peak pressure, $P_{\max }$, for that cycle).

Each borescope has a fish-eye lens at its tip, which provides a larger FoV but also distorts the images. Thus, calibrating the spatial dimensions, so that distances (e.g., $\delta$ ) can be reported in $\mathrm{mm}$ rather than in pixels, is not as straightforward as applying a linear pixel-to-mm scaling. Instead, threedimensional de-warping must be performed. That processing has not yet been undertaken; all distances were calculated in pixels for this document.

When comparing images from different operating conditions or different ignition systems, it was necessary to select crank angles that would provide a fair comparison. A fixed crank angle was unsuitable, since the flame development at a given crank angle would be very dissimilar from one operating point to another or from one ignition system to another. Likewise, using a crank-angle delay relative to the spark timing would not work for all conditions and systems. The mean $\mathrm{MFB}_{00.5}$ in Cylinder 6 for a given operating condition, labeled mean $\left(\mathrm{MFB}_{00.5}\right)$ in this document, was found to be a useful point at which to compare images. In order to provide additional crank angles for comparison, four more angles, evenly spaced (in CAD) from ignition timing to mean $\left(\mathrm{MFB}_{00.5}\right)$ 
FIGURE 6 A diagram of the positions of the normalized crank angles, $\theta_{x / 5}$.

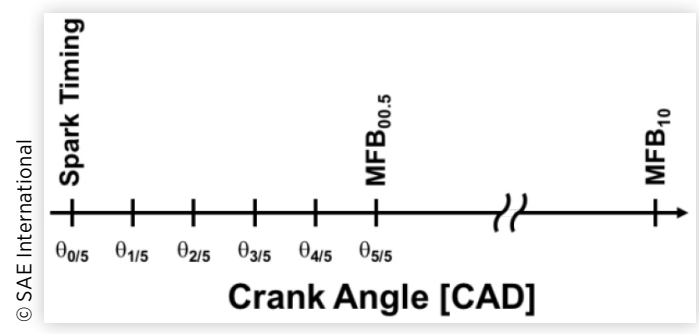

were defined, as shown in Figure 6. The five points in the cycle that resulted were called "normalized crank angles" and were labeled with $\theta$ and a subscript indicating the fraction of time between spark and mean $\left(\mathrm{MFB}_{00.5}\right)$ for each: $\theta_{1 / 5}, \theta_{2 / 5}, \theta_{3 / 5}, \theta_{4 / 5}$, $\theta_{5 / 5}$. Note that, by definition, $\theta_{5 / 5}$ is mean $\left(\mathrm{MFB}_{00.5}\right)$.

\section{Results and Discussion}

\section{Pressure-Derived Results}

Quantitative results are tabulated in Table 3 and Table 4. Ignition delay is defined as the mean (for all 100 cycles) difference (in CAD) between spark timing and $\mathrm{MFB}_{10}$. Combustion duration is defined as the mean difference between the $\mathrm{MFB}_{10}$ and $\mathrm{MFB}_{90}$. BSFC is the brake specific fuel consumption. BS $\mathrm{HC}$ is the brake specific mass of unburned hydrocarbons measured in the exhaust before the catalytic converter. Likewise, $\mathrm{BS} \mathrm{NO}_{x}$ is the brake specific mass of oxides of nitrogen measured in the exhaust before the catalytic converter.

Table 3 shows the effects of the CEI dwell and glow times on these parameters. Each column is color-coded from red for the lowest value to blue for the highest. The two durations had similar impacts. The mean ignition delay and BSFC were essentially unchanged across the conditions tested. CoV(IMEP), BS HC and brake specific carbon monoxide emission (BS CO) favored longer durations, while combustion duration and $\mathrm{BS} \mathrm{NO}_{x}$ favored shorter durations.

Table 4 shows the comparison of the igniters over a range of operating conditions and is color-coded in the same manner as Table 3 . For all of the igniters, lean mixtures yielded reduced $\mathrm{BSFC}, \mathrm{BS} \mathrm{NO}_{x}$, and $\mathrm{BS} \mathrm{CO}$ as well as increased ignition delay, combustion duration, and BS HC. Similarly, EGR-diluted mixtures resulted in lower $\mathrm{BS} \mathrm{NO}_{x}$ and $\mathrm{BSFC}$ as well as higher ignition delay, combustion duration, and BS HC. Unlike lean operation, EGR caused a mild increase in CO emission. When excess air and EGR were introduced together, CoV(IMEP) levels increased significantly. Comparing the igniters reveals that CEI reduced $\mathrm{BS} \mathrm{NO}_{x}$ compared to $65-\mathrm{mJ}$ and $140-\mathrm{mJ}$ igniters, with the exception that the 65-mJ igniter performed the best under EGR-diluted conditions. CEI also reduced BS CO compared to the 65-mJ and 140-mJ igniters, with the exception that the $140-\mathrm{mJ}$ system performed better at the $\lambda=1.6$ and $10 \%$ EGR point. All three igniters had very similar ignition delay and combustion duration characteristics. The 140-mJ system outperformed $65 \mathrm{~mJ}$ system and CEI in terms of $\mathrm{CoV}$ (IMEP) under all lean-and-diluted conditions, and also in terms of BS HC in all common conditions except the stoichiometric undiluted case, in which CEI performed marginally better.

To more clearly illustrate trends in the data, selected results from Table 4 corresponding to two operating conditions, $\lambda=1.0$ with minimal EGR and $\lambda=1.6$ with $10 \%$ EGR, are plotted in Figure 7 and Figure 8. These conditions were selected because they were the most extreme conditions (the easiest and most difficult to ignite). As discussed above,

FIGURE 7 Cycle-to-cycle variation for each igniter at two operating points.

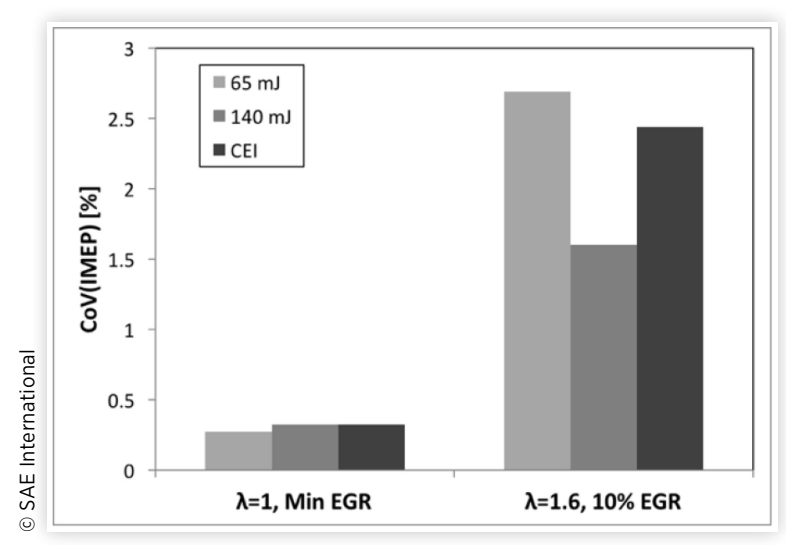

FIGURE 8 Brake-specific emissions for each igniter at two operating points. Top: stoichiometric air/fuel mixture with minimum EGR (3-4\%). Bottom: lean mixture with 10\% EGR.

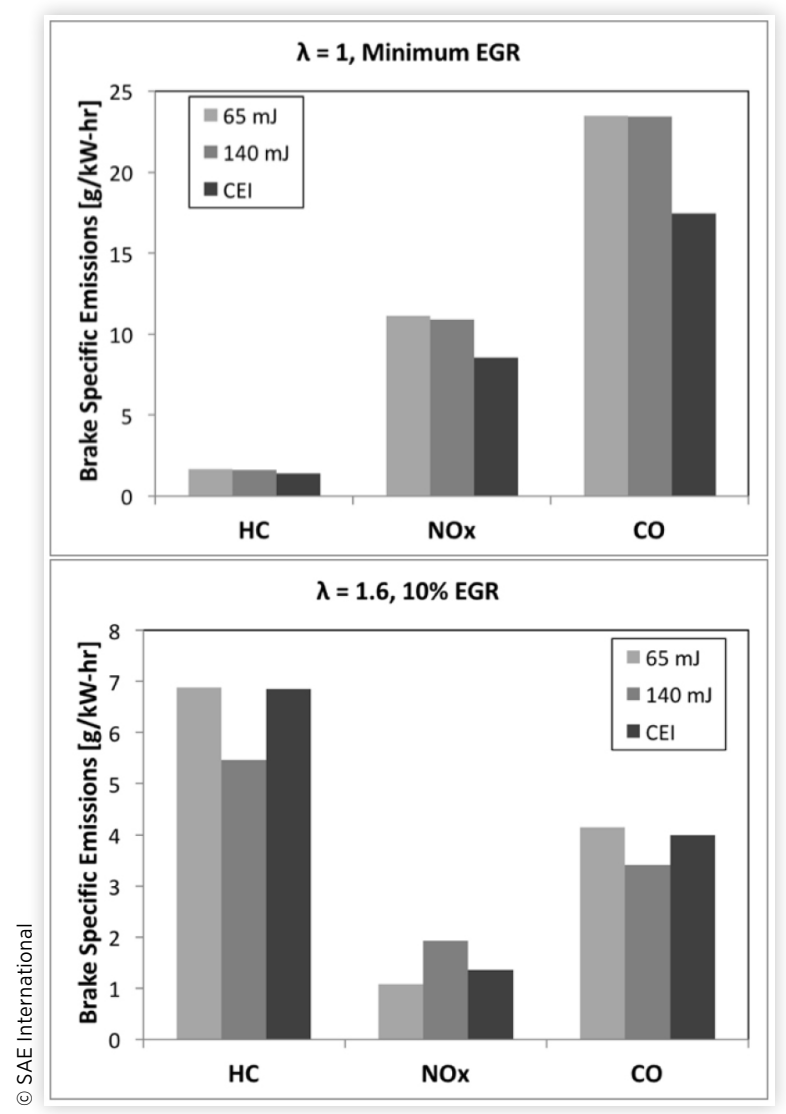


the minimum EGR rate (the rate measured with the EGR valve closed) was nonzero; for all three igniters, it was 3-4\% for the stoichiometric points and $2 \%$ for the lean points. Figure 7 is a plot of $\mathrm{CoV}$ (IMEP) for each igniter for each of these two operating conditions. All three igniters produced comparable CCV for the stoichiometric, minimally diluted condition. All the igniters yielded higher CCV in the lean, dilute condition, but the 140-mJ IDI system performed significantly better than the others. Figure 8 shows the brake specific quantities of three types of emissions (hydrocarbons, oxides of nitrogen, and carbon monoxide). The two operating points are plotted on separate axes to enhance clarity. For the stoichiometric, minimally diluted condition CEI yielded the lowest quantity of all three pollutants. For the lean, dilute condition, the $140-\mathrm{mJ}$ system produced the lowest BS HC and BS CO, but the $65-\mathrm{mJ}$ system produced the lowest $\mathrm{BS} \mathrm{NO}_{x}$.

Figure 9 shows the impact of EGR rate on CCV for the two air/fuel ratios for each igniter. In the stoichiometric case, the igniters produced very similar $\mathrm{CoV}$ (IMEP) values. In the lean case, CEI exhibited a slightly flatter slope between 3\% and $10 \%$ EGR, but the $140-\mathrm{mJ}$ system produced lower $\mathrm{CoV}(\mathrm{IMEP})$ at both points, with a substantially flatter slope, indicating better EGR tolerance.

\section{Image-Derived Results}

The remainder of the Results and Discussion section will focus on image-based data for the operating point with $\lambda=1.6$ and $10 \%$ EGR. This condition was chosen for highlighting in this section because it was the most difficult-to-ignite mixture tested. The integration times for the images reported were 10 $\mu$ s for the $65-\mathrm{mJ}$ system, $20 \mu$ s for the $140-\mathrm{mJ}$ system, and 10 $\mu$ s for CEI.

Figure 10 illustrates the variation between cycles of the three ignition systems studied for this condition. The images in each column were recorded at normalized crank angle $\theta_{3 / 5}$ during different cycles with one ignition system. The cycles used in this figure were chosen subjectively to exemplify the variation between cycles, and the images do not necessarily represent an objective comparison between systems.

\section{FIGURE 9 COV(IMEP) plotted against EGR rate for each igniter.}

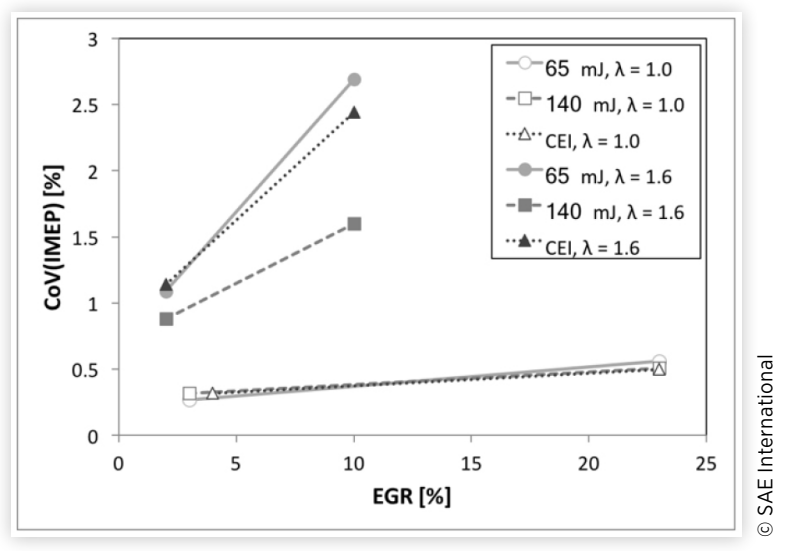

Additionally, as Figure 10 illustrates, IR borescopic images of early flame kernels are consistently visible and clear, even before $\mathrm{MFB}_{00.5}$ (which equals $\theta_{5 / 5}$ ). Thus, high-speed IR imaging can provide valuable information about kernel development at points where data from pressure transducers are unreliable.

Figure 11 illustrates the evolution of an average cycle with each ignition system. The images were recorded at $\theta_{1 / 5}$, $\theta_{2 / 5}, \theta_{3 / 5}, \theta_{4 / 5}$, and $\theta_{5 / 5} \triangleq$ mean $\left(\mathrm{MFB}_{00.5}\right)$. Although these images were recorded with unequal integration times and are presented in false-color scales intended to optimize the view of each individual image (rather than the same color scale for all images), they were all thresholded individually, so the shape the flames can be compared. Both of the highenergy systems produce larger flame kernels, compared to the standard-energy system, at $\theta_{4 / 5}$ and $\theta_{5 / 5}$, as expected. Interestingly, the $140-\mathrm{m}$ J system produced smaller kernels at $\theta_{1 / 5}$ and $\theta_{2 / 5}$, which is counterintuitive. The two highenergy systems produce very similar flame sizes at mean $\left(\mathrm{MFB}_{00.5}\right)$, but the paths the kernels take to arrive at that point are significantly different.

The mean $\left(\mathrm{MFB}_{00.5}\right)$ for this mixture was $-6.11,-6.28$, and $-13.64^{\circ}$ aTDC for the $65-\mathrm{mJ}$ system, the $140-\mathrm{mJ}$ system, and CEI, respectively, meaning that the CEI system consumes the first $0.5 \%$ of the fuel much earlier in the cycle than the other two systems. This timing manifests in Figure 11 as the flame kernels of the 65- and 140-mJ systems being partially obscured by the piston at $\mathrm{MFB}_{00.5}$, as visible at the bottom of the flame in the bottom row of images in the left and middle columns.

Figure 12 shows the standard deviation of the binarized images over 100 cycles to illustrate the cycle-to-cycle variability of the flame boundary location throughout the cycle for the same lean, dilute mixture. The rows were recorded at the same five crank angles as in Figure 11. Early flame growth with $65 \mathrm{~mJ}$ igniter results in slightly wider bands of high variability (indicated by red, orange, or yellow false color) compared to the $140 \mathrm{~mJ}$ igniter and the CEI system. This result is consistent with the higher measured $\mathrm{CoV}(\mathrm{IMEP})$ for that system, as tabulated in Table 4 .

Figure 13 shows centroid clouds at $\theta_{1 / 5}, \theta_{2 / 5}, \theta_{3 / 5}, \theta_{4 / 5}$, and $\theta_{5 / 5}$ for each ignition system. The $65-\mathrm{mJ}$ system's clouds are larger than those of the high-energy systems for all the crank angles shown. The 140-mJ and CEI systems' clouds are approximately the same size through the first three frames, but in the last two frames, the CEI cloud is larger. This result is consistent with the CoV(IMEP) values plotted on the right half of Figure 7; both high-energy systems produce lower cycle-to-cycle variability than the standardenergy system, but the $140-\mathrm{mJ}$ system produces the lowest CCV. Significantly, by the final image, all three systems' images display clear relationships between the centroid locations and the peak pressures associated with them; the centroids with lower peak pressure are located to the upper left (closer to the head), while those associated with higher peak pressure are located to the lower right (farther from the head). This result agrees with intuition; the flames that are centered farther from the head surface are expected have more room to grow before quenching at the walls and to eventually yield higher peak pressures. 
FIGURE 10 Images recorded at the same normalized crank angle, $\theta_{3 / 5}$, during different combustion cycles for all of the ignition systems studied.

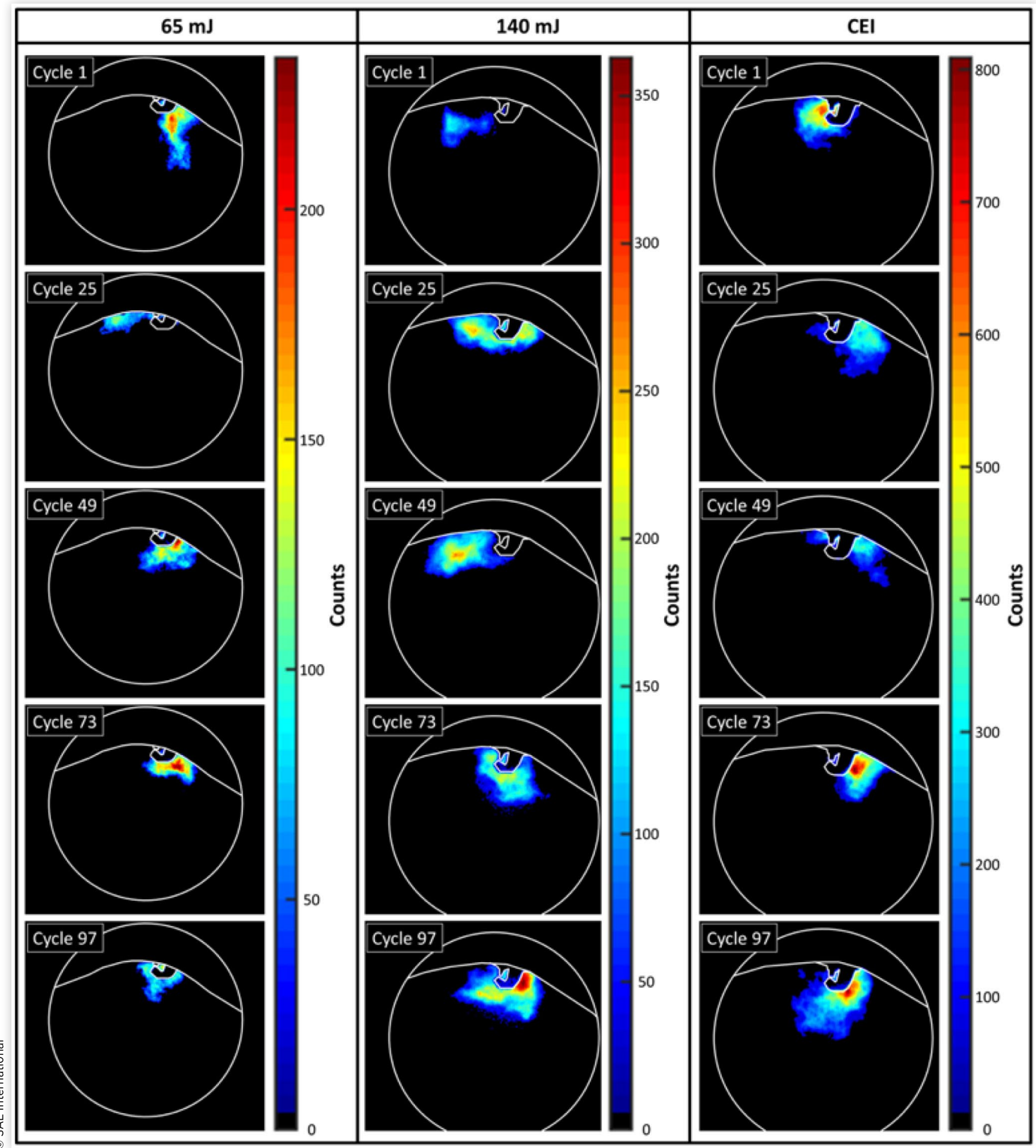

\section{Summary and Conclusions}

In this paper, high-speed infrared in-cylinder imaging, image-based quantitative metrics were combined with standard metrics derived from in-cylinder pressure measurements and emissions benches to investigate the differences between a standard-energy ignition system and two highenergy systems in a six-cylinder, 9.7-liter engine fueled with natural gas. Four operating points (all at $1000 \mathrm{rev} / \mathrm{min}$ engine speed and 6.8 bar IMEP) were studied for each igniter.

Pressure-derived measurements show that, for this engine and these operating points, both of the high-energy igniters (the 140-mJ IDI system and the Controlled Electronic Ignition 
FIGURE 11 Images showing the flame development during an average cycle for each ignition system. Each frame was computed by taking the mean of each pixel across all images recorded at given crank angle for all 100 cycles of the measurement.

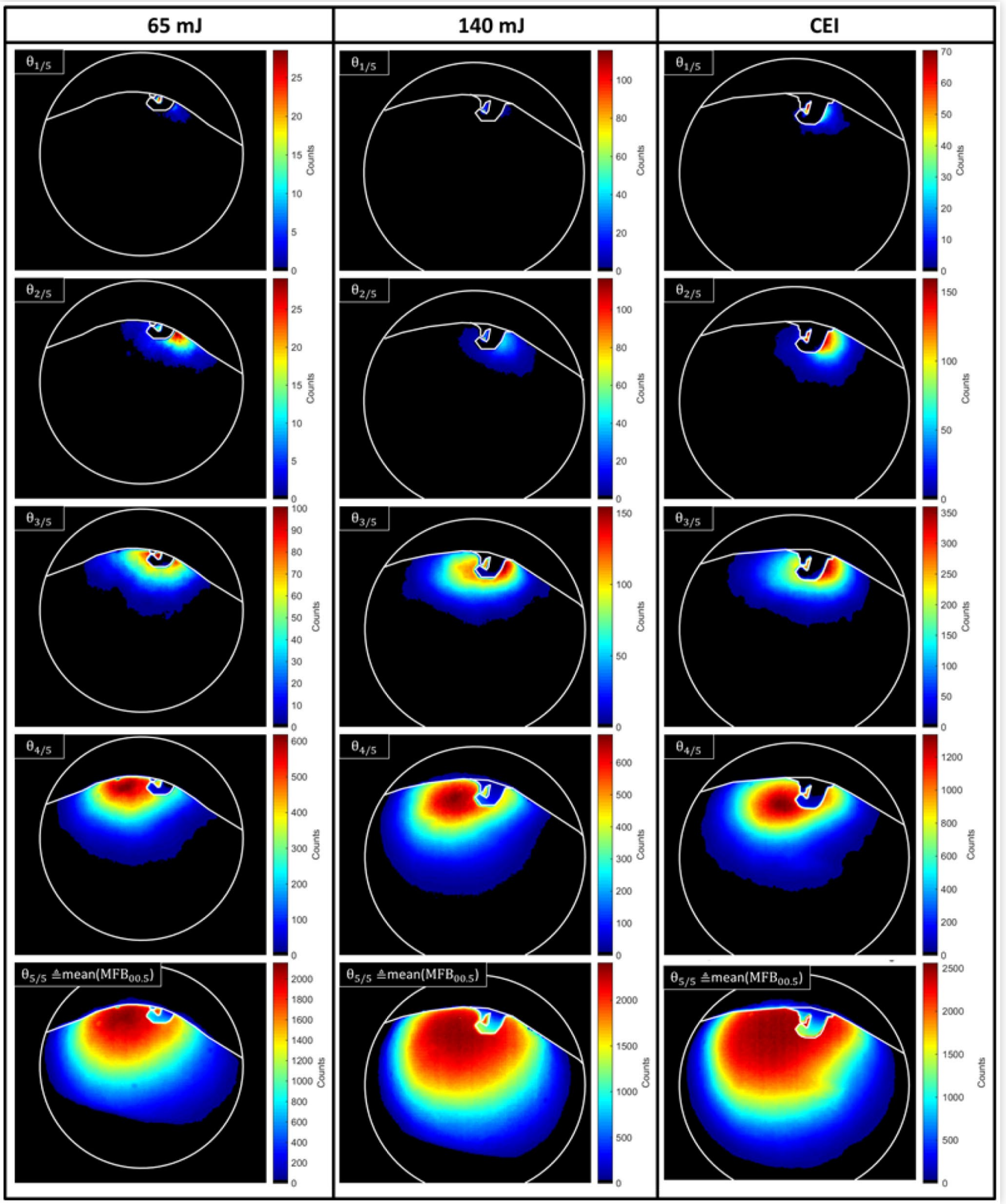


FIGURE 12 The standard deviation of the binarized images of flame development with each ignition system. Each frame was computed by taking the standard deviation of each pixel across all the binarized images recorded at a given crank angle for all 100 cycles of the measurement.

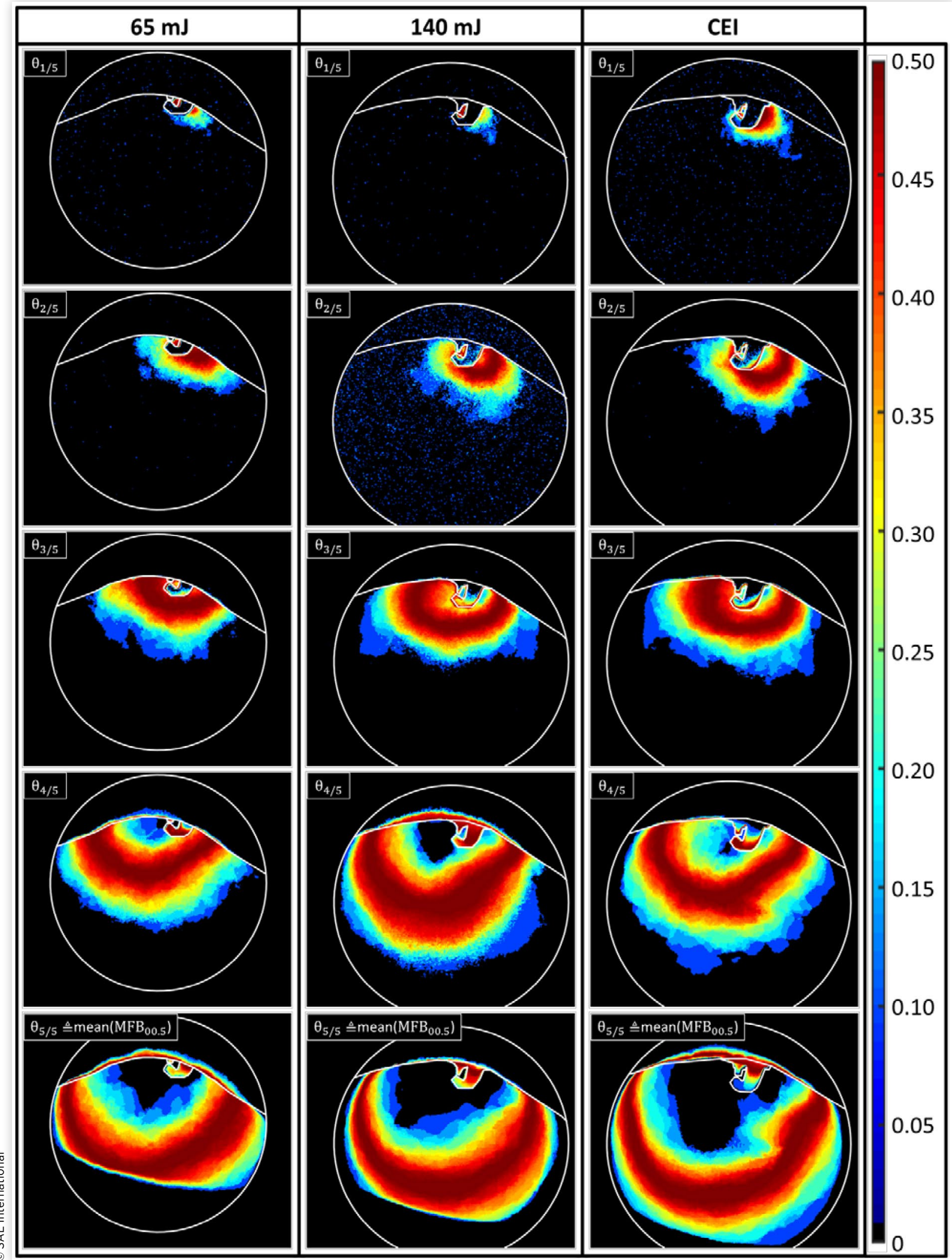


FIGURE 13 Centroid clouds for each ignition system for various crank angles. Each circle marks the location of the centroid of the flame in one cycle at that crank angle and is color-coded according to the $P_{\max }$ of that cycle.

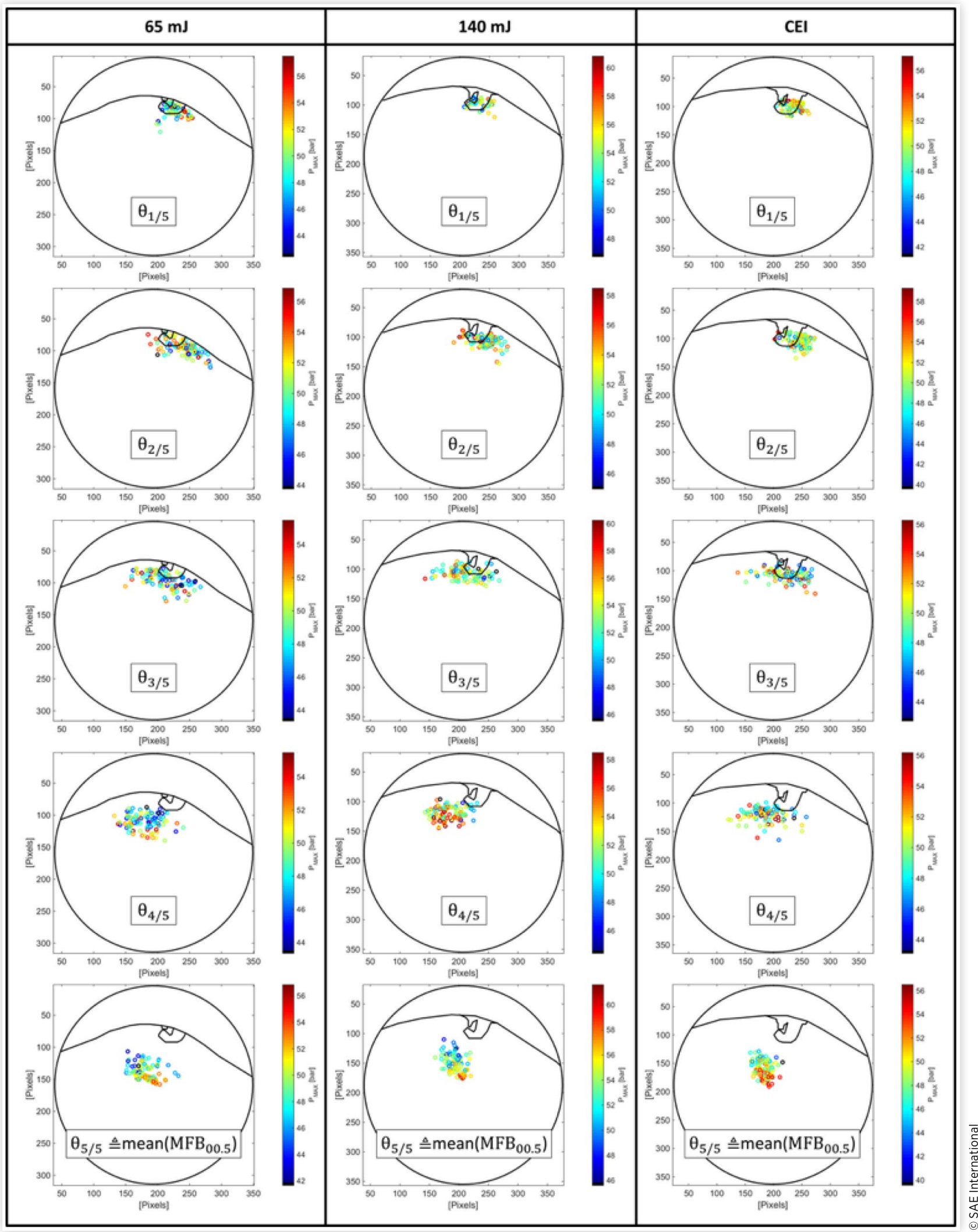


system) demonstrated lower cycle-to-cycle variation compared to $65-\mathrm{mJ}$ igniter for mixtures that were lean, EGR-diluted, or both. In most lean or dilute cases, the 140-mJ IDI system demonstrated the lowest CoV(IMEP). Thus, high-energy igniters demonstrated their capability to ignite leaner and more EGR-diluted mixtures that are difficult to reliably ignite with conventional low-energy igniters. Combustion with such mixtures yielded improved efficiency and emissions, as tabulated in Table 4.

In addition to the pressure-based results, CCV was also studied through borescopic infrared imaging of the early stages of flame-kernel development (from spark timing through $\mathrm{MFB}_{00.5}$ ), where pressure-sensor data is not reliable. Under lean and EGR-diluted operation, CCV of early flame kernels generated by each igniter was visualized by standarddeviation images and flame-centroid tracking. The $65-\mathrm{mJ}$ ignition system produced the largest regions of variability in the images, consistent with the measured CoV(IMEP). The centroid clouds show that cycles with flames farther from the head eventually result in high peak pressures, indicating that engine design and combustion strategy must keep the early flame towards the center of the chamber, and away from surfaces, in order to minimize the quenching and heat losses from the flame to these surfaces.

\section{References}

1. Batelle, Pine \& Associates, "Liquefied Natural Gas Use: Basic Training Manual,” May 1994.

2. Genchi, G. and Pipitone, E., "Octane Rating of Natural GasGasoline Mixtures on CFR Engine," SAE Int. J. Fuels Lubr. 7(3):1041-1049, 2014, doi:10.4271/2014-01-9081.

3. Gross, M., Mazacioglu, A., Kern, J., and Sick, V., "Infrared Borescopic Analysis of Ignition and Combustion Variability in a Heavy-Duty Natural-Gas Engine," SAE Technical Paper 2018-01-0632, 2018.

4. Dale, J.D., Checkel, M., and Smy, P., "Application of High Energy Ignition Systems to Engines," Progress in Energy and Combustion Science 23(5):379-398, 1997, doi:10.1016/S03601285(97)00011-7.

5. Quader, A.A., "What Limits Lean Operation in Spark Ignition Engines-Flame Initiation or Propagation?" SAE Technical Paper $\underline{760760}$, 1976, doi:10.4271/760760.

6. Chen, H., Xu, M., Hung, D.L., and Zhuang, H., "Cycle-ToCycle Variation Analysis of Early Flame Propagation in Engine Cylinder Using Proper Orthogonal Decomposition," Experimental Thermal and Fluid Science 58:48-55, 2014.

7. Hung, D. L.Chen, H. ,Xu, M. ,Yang, J. ,Zhuang H. , 2014. "Experimental Investigation of the Variations of Early Flame Development in a Spark-Ignition Direct-Injection Optical Engine." Journal of Engineering for Gas Turbines and Power 136 (10):101503.

8. Schiffmann, P., "Root Causes of Cycle-to-Cycle Combustion Variations in Spark Ignited Engines," 2016.

9. Schiffmann, P., Reuss, D.L., and Sick, V., "Empirical Investigation of Spark-Ignited Flame-Initiation Cycle-toCycle Variability in a Homogeneous Charge Reciprocating
Engine." International Journal of Engine Research, $1468087417720558,2017$.

10. Alger, T., Gingrich, J., Mangold, B., and Roberts, C., "A Continuous Discharge Ignition System for EGR Limit Extension in SI Engines," SAE International Journal of Engines 4:677-692, 2011, doi:10.4271/2011-01-0661.

11. Ruan, G., Kienzle, D., Roth, D., and Becker, M., "Dual Coil Ignition for Gasoline EGR Engines," MTZ Worldwide 74(3):18-21, 2013.

12. Brandt, M., Hettinger, A., Schneider, A., Senftleben, H.et al., "Extension of Operating Window for Modern Combustion Systems by High Performance Ignition," in Ignition Systems for Gasoline Engines: Third International Conference, November 3-4, 2016, Berlin, Germany, 2017, 3.

13. Ikeda, Y., Nishiyama, A., Katano, H., Kaneko, M. et al., "Research and Development of Microwave Plasma Combustion Engine (Part II: Engine Performance of Plasma Combustion Engine)," 2009.

14. Wolk, B., DeFilippo, A., Chen, J.-Y., Dibble, R. et al., "Enhancement of Flame Development by MicrowaveAssisted Spark Ignition in Constant Volume Combustion Chamber," Combustion and Flame 160(7):1225-1234, 2013.

15. Bohne, S., Rixecker, G., Brichzin, V., and Becker, M., "HighFrequency Ignition System Based on Corona Discharge," MTZ Worldwide 75(1):30-35, 2014.

16. Pineda, D.I., Wolk, B., Chen, J.-Y., and Dibble, R.W., "Application of Corona Discharge Ignition in a Boosted DirectInjection Single Cylinder Gasoline Engine: Effects on Combustion Phasing, Fuel Consumption, and Emissions," SAE Int. J. Engines 9(3):1970-1988, 2016, doi:10.4271/2016-01-9045.

17. Schenk, A., Rixecker, G., and Bohne, S., "Results from Gasoline and CNG Engine Tests with the Corona Ignition System EcoFlash," in Laser Ignition Conference, 2015.

18. Cathey, C.D., Tang, T., Shiraishi, T., Urushihara, T. et al., "Nanosecond Plasma Ignition for Improved Performance of an Internal Combustion Engine," IEEE Transactions on Plasma Science 35(6):1664-1668, 2007.

19. Wisman, D.L., Marcum, S.D., and Ganguly, B.N., "ChemiIon-Current-Induced Dissociative Recombination in Premixed Hydrocarbon/Air Flames," Journal of Propulsion and Power 24(5):1079-1084, 2008.

20. Phuoc, T.X., "Laser-Induced Spark Ignition Fundamental and Applications," Optics and Lasers in Engineering 44(5):351-397, 2006.

21. Groff, E.G. and Krage, M.K., "Microwave Effects on Premixed Flames," Combustion and Flame 56(3):293-306, 1984.

22. Jaggers, H. and Von Engel, A., "The Effect of Electric Fields on the Burning Velocity of Various Flames," Combustion and Flame 16(3):275-285, 1971, doi:10.1016/S0010-2180(71)80098-6.

23. Nakamura, N., Baika, T., and Shibata, Y., "Multipoint Spark Ignition for Lean Combustion," SAE Technical Paper $\underline{852092}, 1985$.

24. Briggs, T., Alger, T., and Mangold, B., "Advanced Ignition Systems Evaluations for High-Dilution SI Engines," SAE Int. J. Engines 7(4):1802-1807, 2014, doi:10.4271/2014-01-2625.

25. Das, M.K. and Thynell, S.T., "Corona, Spark, and Electrothermal-Chemical Plasma Ignition Systems," . In: Handbook of Combustion. (2010). 
26. Maly, R., "Spark Ignition: Its Physics and Effect on the Internal Combustion Engine,”. In: Springer G.S., Hilliard J.C., editors. Fuel Economy in Road Vehicles Powered by Spark Ignition Engines. (Springer Science+Business Media, LLC, 1984), 91-148.

27. Sick, V., "High Speed Imaging in Fundamental and Applied Combustion Research," Proceedings of the Combustion Institute 34(2):3509-3530, 2013, doi:10.1016/j. proci.2012.08.012.

28. Sick, V., Drake, M.C., and Fansler, T.D., "High-Speed Imaging for Direct-Injection Gasoline Engine Research and Development," Experiments in Fluids 49(4):937-947, 2010, doi:10.1007/s00348-010-0891-3.

29. Agrawal, G.P., “Optical Receivers," in Fiber-Optic Communication Systems, 1997, 133-182.

30. Turns, S.R., "An Introduction to Combustion: Concepts and Applications," Third Edition (New York, McGrawHill, 2012).

31. Ludwig, C.B., Malkmus, W., Reardon, J., Thomson, J. et al., "Handbook of Infrared Radiation from Combustion Gases," (Washington, DC, National Aeronautics and Space Administration, 1973).

32. Frank, J., Barlow, R., and Lundquist, C., "Radiation and Nitric Oxide Formation in Turbulent Non-Premixed Jet Flames," Proceedings of the Combustion Institute 28(1):447454, 2000.

33. Brookes, S. and Moss, J., "Measurements of Soot Production and Thermal Radiation from Confined Turbulent Jet Diffusion Flames of Methane," Combustion and Flame 116(1):49-61, 1999.

34. Turns, S.R., “An Introduction to Combustion," Third Edition (New York, McGraw-Hill, 2011).

35. Otsu, N., "A Threshold Selection Method from Gray-Level Histograms," IEEE Transactions on Systems, Man, and Cybernetics 9(1):62-66, 1979.

\section{Acknowledgments}

The information, data, or work presented herein was funded in part by the Office of Energy Efficiency and Renewable Energy (EERE), U.S. Department of Energy, under Award Number DE-EE0007307. We also thank Dr. Hao Chen and Angela Wu for their help with software and James Elkins for engine-head modifications.

\section{Definitions and Abbreviations}

BS - brake specific

BSFC - brake specific fuel consumption

CAD - crank-angle degree

CEI - Controlled Electronic Ignition

CoV(IMEP) - coefficient of variation of IMEP

EGR - exhaust-gas recirculation

HC - hydrocarbons

HD - heavy duty

IDI - inductive-discharge ignition

IMEP - indicated mean effective pressure

IR - infrared

mean $\left(\mathrm{MFB}_{\mathbf{0 0 . 5}}\right)$ - the mean value of $\mathrm{MFB}_{00.5}$, evaluated over all cycles of a measurement

MFB $_{x}$ - the crank angle at which $x \%$ of the fuel mass has been burned.

$\boldsymbol{P}_{\text {max }}$ - peak in-cylinder pressure

$\lambda$ - air/fuel equivalence ratio

$\boldsymbol{\theta}_{x / 5}$ - the crank angle $x / 5$ of the time (in CAD) between spark timing and mean $\left(\mathrm{MFB}_{00.5}\right)$

${ }^{\circ}$ aTDC - degrees after top dead center

\section{Contact Information}

\section{Michael C. Gross}

University of Michigan

W. E. Lay Automotive Engineering Laboratory

1231 Beal Avenue

Ann Arbor MI 48109-2133

(734) 936-0426

mcgross@umich.edu

All rights reserved. No part of this publication may be reproduced, stored in a retrieval system, or transmitted, in any form or by any means, electronic, mechanical, photocopying, recording, or otherwise, without the prior written permission of the copyright holder.

Positions and opinions advanced in this paper are those of the author(s) and not necessarily those of SAE International. The author is solely responsible for the content of the paper.

ISSN 0148-7191 